\title{
FORECASTING THE REAL OUTPUT USING FRACTIONALLY INTEGRATED
} TECHNIQUES

\author{
Luis A. Gil-Alana* \\ Humboldt Universitat zu Berlin, Institut fur Statistik und Okonometrie, Berlin, Germany \\ University of Navarre, Department of Economics, Pamplona, Spain
}

\begin{abstract}
The annual structure of the real GDP in the UK, France, Germany and Italy is examined in this article by means of fractionally integrated techniques. Using a version of a testing procedure due to Robinson (1994), we show that the series can be specified in terms of I(d) statistical models with $d$ higher than 1 . Thus, the series are nonstationary and non-mean-reverting. The forecasting properties of the selected models for each country are also examined at the end of the article.
\end{abstract}

Keywords: Fractional integration; Long memory; Nonstationarity.

JEL Classification: C22.

Correspondence author: Luis A. Gil-Alana

Humboldt Universitat zu Berlin

Institut fur Statistik und Okonometrie

Spandauer Str. 1

D-10178 Berlin

GERMANY

Phone: 00493020931682

Fax: 00493020935712

Email: alana@wiwi.hu-berlin.de

\footnotetext{
* Financial support from Macroeconomic Modelling and Policy Analysis in a Changing World Grant No. "L116251013" is gratefully acknowledged. Also, the author also acknowledges financial support from the Deutsche Forschungsgemeinschaft, SFB 373.
} 


\section{Introduction}

In this article we model the real GDP series in France, Italy, Germany and the U.K. by means of fractionally integrated techniques. For this purpose, we make use of a version of the tests of Robinson (1994) that permits us to incorporate deterministic trends and to specify the model in a fully parametric way. The tests have standard null and local limit distributions and are easy to implement in raw time series. The forecasting properties of the selected models for each country are also examined, the results showing that all series are nonstationary and non-meanreverting, i.e., with the effect of the shocks persisting forever. Furthermore, the fact that the series appear to be $\mathrm{I}(\mathrm{d})$ with $\mathrm{d}>1$ implies that the standard approach of taking first differences to get $\mathrm{I}(0)$ stationarity may result in series still with a component of long memory behaviour. The outline of the paper is as follows: Section 2 briefly describes the concept of fractional integration and presents the version of the tests of Robinson (1994) used in the paper. In Section 3, the tests are applied to the annual structure of the GDP in the four countries. Section 4 examines different potential models for each country and also investigates the forecasting properties of the selected models based on 10 out-of-sample observations. Section 5 concludes.

\section{Testing of fractional integration}

Following the parameterization of unit roots proposed by Bhargava (1986), Schmidt and Phillips (1992) and others, we can consider the model,

$$
y_{t}=\beta^{\prime} z_{t}+x_{t}, \quad t=1,2, \ldots
$$

where $\beta$ is a $(\mathrm{kx} 1)$ vector of unknown parameters; $\mathrm{z}_{\mathrm{t}}$ is a $(\mathrm{kx} 1)$ vector of deterministic regressors, and the regression errors $\mathrm{x}_{\mathrm{t}}$ are such that:

$$
(1-L)^{d} x_{t}=u_{t}, \quad t=1,2, \ldots
$$

where $u_{t}$ is an $I(0)$ process defined as a covariance stationary process with spectral density function that is positive and finite at the zero frequency. Clearly, if $d=0$ in $(2), x_{t}=u_{t}$, and a 
'weakly autocorrelated' $x_{t}$ is allowed for; however, if $d>0, x_{t}$ is said to be a long memory process, also called 'strong dependent', or 'strongly autocorrelated', so-named because of the strong association between observations widely separated in time. Note that the polynomial in (2) can be expressed in terms of its Binomial expansion such that for all real d,

$$
(1-L)^{d}=1-d L+\frac{d(d-1)}{2 !} L^{2}-\frac{d(d-1)(d-2)}{3 !} L^{3}+\ldots
$$

This type of processes were introduced by Granger and Joyeux (1980), Granger (1980, 1981) and Hosking (1980), (though earlier work by Adenstedt, 1974, and Taqqu, 1975, showed an awareness of its representation), and were theoretically justified in terms of aggregation of ARMA processes by Robinson (1978), Granger (1980), and more recently, in terms of the duration of shocks by Parke (1999). The parameter d plays a crucial role from both statistical and economic viewpoints. Thus, if $d \in(0,0.5), x_{t}$ will be covariance stationary and meanreverting, with the effect of the shocks dying away in the long run; if $d \in[0.5,1), x_{t}$ will be nonstationary in the sense that the partial sums are non-summable, though still will be meanreverting; finally, if $\mathrm{d} \geq 1, \mathrm{x}_{\mathrm{t}}$ will be nonstationary and non-mean-reverting, with the effect of the shocks persisting forever. Complete surveys of long memory processes can be found in Beran (1994) and Baillie (1996), and empirical applications based on fractional models like (2) are Diebold and Rudebusch (1989), Baillie and Bollerslev (1994) and more recently, Gil-Alana and Robinson (1997).

Robinson (1994) proposed a Lagrange Multiplier (LM) test of the null hypothesis:

$$
H_{o}: d=d_{o}
$$

in (1) and (2) for any real value $\mathrm{d}_{\mathrm{o}}$. Specifically, the test statistic is given by:

$$
\hat{r}=\left(\frac{T}{\hat{A}}\right)^{1 / 2} \frac{\hat{a}}{\hat{\sigma}^{2}},
$$

where $\mathrm{T}$ is the sample size and 


$$
\begin{gathered}
\hat{a}=\frac{-2 \pi}{T} \sum_{j=1}^{T-1} \psi\left(\lambda_{j}\right) g\left(\lambda_{j} ; \hat{\tau}\right)^{-1} I\left(\lambda_{j}\right) ; \quad \hat{\sigma}^{2}=\frac{2 \pi}{T} \sum_{j=1}^{T-1} g\left(\lambda_{j} ; \hat{\tau}\right)^{-1} I\left(\lambda_{j}\right) ; \\
\hat{A}=\frac{2}{T}\left(\sum_{j=1}^{T-1} \psi\left(\lambda_{j}\right)^{2}-\sum_{j=1}^{T-1} \psi\left(\lambda_{j}\right) \hat{\varepsilon}\left(\lambda_{j}\right)^{\prime} \times\left(\sum_{j=1}^{T-1} \hat{\varepsilon}\left(\lambda_{j}\right) \hat{\varepsilon}\left(\lambda_{j}\right)^{\prime}\right)^{-1} \times \sum_{j=1}^{T-1} \hat{\varepsilon}\left(\lambda_{j}\right) \psi\left(\lambda_{j}\right)\right) \\
\psi\left(\lambda_{j}\right)=\log \left|2 \sin \frac{\lambda_{j}}{2}\right| ; \quad \hat{\varepsilon}\left(\lambda_{j}\right)=\frac{\partial}{\partial \tau} \log g\left(\lambda_{j} ; \hat{\tau}\right) ; \quad \lambda_{j}=\frac{2 \pi j}{T} .
\end{gathered}
$$

$\mathrm{I}\left(\lambda_{\mathrm{j}}\right)$ is the periodogram of $\hat{u}_{t}$ defined as

$$
\hat{u}_{t}=(1-L)^{d_{o}} y_{t}-\beta^{\prime} w_{t} ; \hat{\beta}=\left(\sum_{t=1}^{T} w_{t} w_{t}{ }^{\prime}\right)^{-1} \sum_{t=1}^{T} w_{t}(1-L)^{d_{o}} y_{t} ; \quad w_{t}=(1-L)^{d_{o}} z_{t} \text {, }
$$

and $\mathrm{g}$ above is a known function coming from the spectral density function of $\hat{u}_{t}$ : $f(\lambda ; \tau)=\frac{\sigma^{2}}{2 \pi} g(\lambda ; \tau)$, with $\hat{\tau}$ obtained by minimising $\sigma^{2}(\tau)$. Note that if $\mathrm{u}_{\mathrm{t}}$ is white noise, $\mathrm{g} \equiv$ 1 and, if $u_{t}$ is an AR process of form: $\phi(L) u_{t}=\varepsilon_{t}, g=\left|\phi\left(e^{i \lambda}\right)\right|^{-2}$, so that the AR coefficients are function of $\tau$.

Robinson (1994) established that under certain regularity conditions:

$$
\hat{r} \rightarrow_{d} N(0,1) \quad \text { as } \quad T \rightarrow \infty \text {. }
$$

Thus, an approximated one-sided test of $\mathrm{H}_{\mathrm{o}}(3)$ against the alternative: $\mathrm{H}_{\mathrm{a}}: \mathrm{d}>\mathrm{d}_{\mathrm{o}}$, will reject $\mathrm{H}_{\mathrm{o}}$ if $\hat{r}>\mathrm{z}_{\alpha}$, where the probability that a standard normal variate exceeds $\mathrm{z}_{\alpha}$ is $\alpha$, and conversely, a one-sided test of $\mathrm{H}_{\mathrm{o}}(3)$ against $\mathrm{H}_{\mathrm{a}}$ : $\mathrm{d}<\mathrm{d}_{\mathrm{o}}$, will reject $\mathrm{H}_{\mathrm{o}}$ if $\hat{r}<-\mathrm{z}_{\alpha}$. As these rules indicate, we are in a classical large-sample testing situation by reasons described by Robinson (1994), who also showed that the above tests are efficient in the Pitman sense against local departures from the null. This version of the tests of Robinson (1994) was used in empirical applications in Gil-Alana and Robinson (1997) and Gil-Alana (2000) and, other versions of his tests based on seasonal (quarterly and monthly) and cyclical models can be found respectively in GilAlana and Robinson (2001) and Gil-Alana (1999, 2001). 


\section{Testing the order of integration in the real output}

The time series data analysed in this section correspond to the annual data of the real GPD in France, Germany, Italy and the U.K. for the time period 1870-2000, the last ten observations being discarded for forecasting purposes.

Denoting any of the series $\mathrm{y}_{\mathrm{t}}$, we employ throughout model (1) and (2), with $\mathrm{z}_{\mathrm{t}}=(1, \mathrm{t})^{\prime}, \mathrm{t}$ $\geq 1,0$ otherwise, i.e.,

$$
\begin{aligned}
y_{t}=\alpha+\beta t+x_{t}, & t=1,2, \ldots \\
(1-L)^{d} x_{t}=u_{t}, & t=1,2, \ldots,
\end{aligned}
$$

testing $H_{o}$ (3) for values of $d_{o}$ equal to $0,(0.10)$, 2, i.e., we test for a unit root $(d=1)$; for $I(2)$ processes $(d=2)$; as well as other fractionally integrated possibilities. We study separately the cases of $\alpha=\beta=0$ a priori, (i.e., including no regressors in the undifferenced regression); $\alpha$ unknown and $\beta=0$ a priori, (i.e., including an intercept), and finally, $\alpha$ and $\beta$ unknown. Initially, in Table 1, we assume that $\mathrm{u}_{\mathrm{t}}$ is white noise, though later we also allow for weakly parametrically autocorrelated disturbances.

\section{(Table 1 about here)}

The test statistic reported across Table 1 is the one-sided one given by $\hat{r}$ in (4). Thus, significantly positive values of this are consistent with orders of integration higher than $\mathrm{d}_{0}$, whereas significantly negative ones implies values of $d$ smaller than that hypothesized under the null. A notable feature observed across Table 1 is the fact that $\hat{r}$ monotonically decreases with $d_{0}$. This is something to be expected since it is a one-sided test statistic. Thus, for example, if $H_{o}(3)$ is rejected when $d=1$ against alternatives of form: $d>1$, an event more significant result in this direction should be expected when $d=0.75$ or 0.50 are tested. We see in this table that the unit root null hypothesis is rejected in all cases in favour of more nonstationary hypotheses, and the non-rejection values of $d$ are very similar for the different cases of no regressors, an intercept and an intercept and a linear time trend. These values are 
1.30, 1.40 and 1.50 in case of France and Germany; 1.30 and 1.40 for Italy, and these two values along with 1.20 and 1.60 for the U.K. However, the significance of the above results may be in large part due to the un-accounted for $\mathrm{I}(0)$ autocorrelation in $\mathrm{u}_{\mathrm{t}}$. Thus, in Tables 2 and 3 we allow weakly autocorrelated disturbances. In particular, we impose AR(1) and AR(2) disturbances. Higher order autoregressions were also tried and the results were very similar to those reported across the tables.

\section{(Tables 2 and 3 about here)}

Table 2 starts with AR(1) $u_{t}$. We see that for France, Italy and Germany, the orders of integration are higher than 1, oscillating between 1.20 and 1.50 in case of France; being 1.30 and 1.40 for Italy; and 1.10 and 1.20 for Germany; while for the U.K., the unit root null hypothesis $(\mathrm{d}=1)$ cannot be rejected along with $\mathrm{d}=1.10$ and 1.20 . Imposing $\operatorname{AR}(2)$ disturbances, (in Table 3), there is a larger proportion of non-rejection values compared with Table 2, probably due to the larger number of parameters required in the estimation, however, the same conclusions as in the previous table hold, with France as the most nonstationary series, followed by Italy and Germany, while U.K. appears as the less nonstationary one, observing non-rejection values even for the unit root case.

In view of these results, we can conclude the analysis of these tables by saying that the real GDP series are nonstationary for the four countries, with the orders of integration being equal to or higher than 1 in case of the U.K. and being strictly higher than 1 for France, Italy and Germany. These results are obtained independently of the inclusion or not of deterministic trends and of the different ways of modelling the $\mathrm{I}(0)$ disturbances.

\section{Potential model specifications and prediction}

In this section we are concerned with which might be the best model specification for each series according to two different criteria. First, we choose for each country the models which best fit the data in a way such that the residuals are the closest to white noise. Then, we look at 
the models in terms of forecasting, trying to predict the last ten obsrvations and looking at the mean square errors.

\section{(Table 4 about here)}

Table 4 reports for each series nine different models, each corresponding to the different cases for $\mathrm{z}_{\mathrm{t}}$, (i.e., with no regressors, with an intercept, and with an intercpet and a linear time trend), and to the different types of $\mathrm{I}(0)$ disturbances, (i.e., white noise, $\operatorname{AR}(1)$ and $\operatorname{AR}(2)$ ), taking the value of $d$ for each model which produces the lowest $|\hat{r}|$ across $d_{0}$. The intuition behind this is that the model with the lowest $|\hat{r}|$ will give us the closest residuals to white noise. We see in this table that for France the values of $d$ range between 1.34 (in case of white noise $u_{t}$ and no regressors) and $1.55\left(\operatorname{AR}(2) \mathrm{u}_{\mathrm{t}}\right.$ and $\left.\mathrm{z}_{\mathrm{t}}=0\right)$; for Italy, the values are between 1.30 and 1.47; for Germany, between 1.14 and 1.34, and finally for the U.K., they oscillate between 1.08 (with $\operatorname{AR}(1) u_{t}$ with an intercept) and 1.38 (with white noise $u_{t}$ and a linear time trend). Thus, in all cases we observe orders of integration higher than 1, implying that the series are nonstationary and non-mean reverting, with the effects of the schocks persisting forever. Furthermore, the fact that $\mathrm{d}$ is higher than 1 also implies that the standard approach of taking first differences may still lead to series with a component of long memory behaviour (i.e., I(d) with $\mathrm{d}>0$ ).

\section{(Table 5 about here)}

In Table 5, we have calculated the mean square errors of the nine selected models for each country based on the last ten observations. The first thing that we observe here is that the inclusion of an intercept and a linear trend produces larger mean square errors for all countries compared with the cases of no regressors or of an intercept, implying that a linear time trend may not be required when modelling these series. We see that according to the mean square errors, the best models change in case of the first three or four predictions, however, if we predict for more than four periods ahead, for each country we observe a model that performs the best. Thus, for France, it appears to be an I(1.37) with an intercept; for Italy, it is a pure 
$\mathrm{I}(1.30)$; for Germany, an $\mathrm{I}(1.33)$ with $\mathrm{AR}(2) \mathrm{u}_{\mathrm{t}}$; while for the UK, it is an $\mathrm{I}(1.09)$ with an intercept and $\mathrm{AR}(2)$ disturbances.

\section{Conclusions}

The annual structure of the real GDP in France, Italy, Germany and the U.K. has been examined in this article by means of fractionally integrated techniques. Using a version of the tests of Robinson (1994) for testing I(d) statistical models, we show that all series may be specifed in terms of $\mathrm{I}(\mathrm{d})$ models with $\mathrm{d}>1$. This result is obtained independently of the inclusion or not of deterministic trends and of the different ways of modelling the $\mathrm{I}(0)$ disturbances. In order to be more specific about the degree of integration of each series we choose the value of $d$ which produces the lowest statistic in absolute value across $d$. The results indicate that the real GDP in France is the most nonstationary series with d fluctuating between 1.34 and 1.55. This value is between 1.30 and 1.47 in case of Italy, and between 1.14 and 1.34 for Germany. Finally, the results for the UK suggest that d oscillates between 1.08 and 1.38. We also analysed the forecasting properties of the selected models and, according to the mean square errors based on the last ten observations, the preferred models appear to be with orders of integration of 1.37 for France, 1.33 for Germany, 1.30 for Italy, and 1.09 for the UK. Thus, we conclude by saying that even taking first differences, the series have a component of long memory behaviour. 


\section{References}

Adenstedt, R.K., 1974, On large sample estimation for the mean of a stationary random sequence, Annals of Statistics 2, 1095-1107.

Baillie, R.T., 1996, Long memory and fractional integration in econometrics, Journal of Econometrics 73, 5-59.

Baillie, R.T. and T. Bollerslev, 1994, Cointegration, fractional cointegration and exchange rate dynamics, Journal of Finance 49, 737-745.

Beran, J., 1994, Statistics for long memory processes, Monographs on statistics and applied probability 61, Chapman and Hall, New York, NY.

Bhargava, A., 1986, On the theory of testing of unit roots in observed time series, Review of Economic Studies 53, 369-384.

Diebold, F.X. and G.P. Rudebusch, 1989, Long memory and persistence in aggregate output, Journal of Monetary Economics 24, 189-209.

Gil-Alana, L.A., 1999, Testing fractional integration with monthly data, Economic Modelling $16,613-629$.

Gil-Alana, L.A., 2000, Mean reversion in the real exchange rates, Economics Letters 69, 285288.

Gil-Alana, L.A., 2001, Testing stochastic cycles in macroeconomic time series, forthcoming in Journal of Time Series Analysis.

Gil-Alana, L.A. and P.M. Robinson, 1997, Testing of unit and fractional roots in macroeconomic time series, Journal of Econometrics 80, 247-268.

Gil-Alana, L.A. and P.M. Robinson, 2001, Testing seasonal fractional integration in the UK and Japanese consumption and income, Journal of Applied Econometrics 16, 95-114.

Granger, C.W.J., 1980, Long memory relationships and the aggregation of dynamic models, Journal of Econometrics 14, 227-238. 
Granger, C.W.J., 1981, Some properties of time series data and their use in econometric model specification, Journal of Econometrics 16, 121-130.

Granger, C.W.J. and R. Joyeux, 1980, An introduction to long range time series models and fractional differencing, Journal of Time Series Analysis 1, 15-30.

Hosking, J.R.M., 1981, Fractional differencing, Biometrika 68, 165-176.

Parke, W.R.,1999, What is fractional integration?, The Review of Economics and Statistics 81, 632-638.

Robinson, P.M., 1978, Statistical inference for a random coefficient autoregressive model, Scandinavian Journal of Statistics 5, 163-168.

Robinson, P.M., 1994, Efficient tests of nonstationary hypotheses, Journal of the American Statistical Association 84, 1420-1437.

Schmidt, P. and P.C.B. Phillips, 1992, LM tests for a unit root in the presence of deterministic trends, Oxford Bulletin of Economics and Statistics 54, 257-287.

Taqqu, M.S., 1975, Weak convergence to fractional Brownian to Rosenblatt processes, Z. Wahrsch. Verw. Geb. 31, 287-302. 


\section{TABLE 1}

Testing the order of integration with white noise disturbances

\begin{tabular}{|c|c|c|c|c|c|c|c|c|c|c|c|c|}
\hline Country & $\mathrm{z}_{\mathrm{t}} / \mathrm{d}_{\mathrm{o}}$ & 0.80 & 0.90 & 1.00 & 1.10 & 1.20 & 1.30 & 1.40 & 1.50 & 1.60 & 1.70 & 1.80 \\
\hline \multirow{3}{*}{ France } & --- & 21.06 & 16.59 & 11.42 & 6.71 & 3.14 & 0.70 & -0.90 & -1.99 & -2.75 & -3.31 & -3.74 \\
\hline & 1 & 20.49 & 16.88 & 12.18 & 7.52 & 3.80 & 1.21 ' & $-0.49^{\prime}$ & -1.62 & -2.41 & -2.99 & -3.43 \\
\hline & $(1, t)^{\prime}$ & 20.55 & 16.69 & 12.30 & 8.01 & 4.37 & 1.63, & $-0.27^{\prime}$ & $-1.54^{\prime}$ & -2.39 & -2.99 & -3.44 \\
\hline \multirow{3}{*}{ Italy } & --- & 22.26 & 17.83 & 12.19 & 6.78 & 2.71 & 0.07 & -1.53, & -2.53 & -3.18 & -3.64 & -3.99 \\
\hline & 1 & 21.68 & 17.82 & 12.49 & 7.11 & 2.91 & 0.16 , & $-1.51 '$ & -2.53 & -3.20 & -3.66 & -4.00 \\
\hline & $(1, t)^{\prime}$ & 21.56 & 17.47 & 12.56 & 7.67 & 3.59 & 0.65 & $-1.26^{\prime}$ & -2.44 & -3.17 & -3.66 & -4.01 \\
\hline \multirow{3}{*}{ Germany } & --- & 17.48 & 13.04 & 8.50 & 4.74 & 2.07 & 0.31 , & -0.84 & -1.64 & -2.22 & -2.67 & -3.04 \\
\hline & 1 & 16.88 & 12.78 & 8.39 & 4.70 & 2.06 & 0.33' & -0.80 & $-1.59^{\prime}$ & -2.16 & -2.61 & -2.97 \\
\hline & $(1, t)^{\prime}$ & 16.45 & 12.42 & 8.47 & 5.08 & 2.48 & $0.62 '$ & -0.65 , & -1.52, & -2.14 & -2.60 & -2.97 \\
\hline \multirow{3}{*}{ U. K. } & --- & 16.91 & 11.93 & 7.34 & 3.84 & $1.44^{\prime}$ & -0.14, & $-1.22^{\prime}$ & -1.99 & -2.57 & -3.02 & -3.40 \\
\hline & 1 & 16.78 & 12.88 & 8.59 & 4.99 & 2.43 & $0.74^{\prime}$ & $-0.37^{\prime}$ & $-1.17^{\prime}$ & -1.78 & -2.28 & -2.71 \\
\hline & $(1, t)^{\prime}$ & 16.47 & 12.54 & 8.72 & 5.46 & 2.93 & 1.10 ' & -0.17 & -1.08 ' & -1.75 & -2.22 & -2.71 \\
\hline
\end{tabular}

\footnotetext{
' and in bold: Non-rejection values at the $95 \%$ significance level.
} 


\section{TABLE 2}

Testing the order of integration with $\mathrm{AR}(1)$ disturbances

\begin{tabular}{|c|c|c|c|c|c|c|c|c|c|c|c|c|}
\hline Country & $\mathrm{z}_{\mathrm{t}} / \mathrm{d}_{\mathrm{o}}$ & 1.00 & 1.10 & 1.20 & 1.30 & 1.40 & 1.50 & 1.60 & 1.70 & 1.80 & 1.90 & 2.00 \\
\hline \multirow{3}{*}{ France } & --- & 3.90 & 3.35 & 1.94 & $\mathbf{0 . 6 0}$ & $-0.47^{\prime}$ & -1.30 & -1.94 & -2.46 & -2.89 & -3.26 & -3.58 \\
\hline & 1 & 2.66 & 2.51 & 1.32 & -0.03 & -1.12 & -1.92 & -2.51 & -2.97 & -3.34 & -3.66 & -3.94 \\
\hline & $(1, t)^{\prime}$ & 2.32 & 2.74 & 1.64 & 0.29 & $-0.91^{\prime}$ & -1.83 & -2.49 & -2.97 & -3.35 & -3.66 & -3.94 \\
\hline \multirow{3}{*}{ Italy } & --- & 5.84 & 4.73 & 2.53 & 0.54 & -0.91 ' & -1.90 & -2.56 & -3.04 & -3.39 & -3.69 & -3.94 \\
\hline & 1 & 4.39 & 4.32 & 2.34 & 0.34 & -1.15, & -2.15 & -2.82 & -3.28 & -3.62 & -3.90 & -4.12 \\
\hline & $(1, t)^{\prime}$ & 4.89 & 4.59 & 2.82 & 0.83 , & -0.83, & -2.02 & -2.78 & -3.28 & -3.63 & -3.90 & -4.13 \\
\hline \multirow{3}{*}{ Germany } & --- & 2.62 & 0.94 & -0.62, & -1.76 & $\begin{array}{l}-2.54 \\
\end{array}$ & -3.05 & -3.41 & -3.68 & -3.91 & -4.10 & $\begin{array}{l}-4.26 \\
\end{array}$ \\
\hline & 1 & 1.72 & 0.51 , & -0.88 , & -1.96 & -2.69 & -3.18 & -3.53 & -3.79 & -4.00 & -4.18 & -4.35 \\
\hline & $(1, t)^{\prime}$ & 2.05 & 0.78' & -0.56 ' & -1.69 & -2.53 & -3.11 & -3.50 & -3.78 & -4.00 & -4.18 & -4.35 \\
\hline \multirow{3}{*}{ U. K. } & --- & 1.10 ' & 0.14 & -0.73 & -1.38, & -1.84 & -2.15 & -2.40 & -2.60 & -2.79 & -2.97 & -3.14 \\
\hline & 1 & $0.51^{\prime}$ & -0.21 ' & -1.27 & -2.04 & -2.51 & -2.78 & -2.95 & -3.06 & -3.16 & -3.26 & -3.36 \\
\hline & $(1, t)^{\prime}$ & 1.08 & 0.08 & -0.94 & -1.77 & -2.34 & -2.70 & -2.92 & -3.05 & -3.16 & -3.26 & -3.37 \\
\hline
\end{tabular}

' and in bold: Non-rejection values at the 95\% significance level. 
TABLE 3

Testing the order of integration with $\mathrm{AR}(2)$ disturbances

\begin{tabular}{|c|c|c|c|c|c|c|c|c|c|c|c|c|}
\hline Country & $\mathrm{z}_{\mathrm{t}} / \mathrm{d}_{\mathrm{o}}$ & 1.00 & 1.10 & 1.20 & 1.30 & 1.40 & 1.50 & 1.60 & 1.70 & 1.80 & 1.90 & 2.00 \\
\hline \multirow{3}{*}{ France } & --- & 2.46 & $1.44^{\prime}$ & $1.13^{\prime}$ & 0.87 & 0.50 & $0.15^{\prime}$ & $-0.17^{\prime}$ & $-0.46^{\prime}$ & -1.74 & -2.02 & -2.31 \\
\hline & 1 & 2.61 & -1.75 & 1.09' & $0.56{ }^{\prime}$ & $0.10^{\prime}$ & -0.31 & -0.65 & -1.04 ' & -1.64 & -1.93 & -2.67 \\
\hline & $(1, t)^{\prime}$ & 2.11 & 1.93 & 1.92 & 0.68 & 0.21 ' & -0.26 , & -0.65, & -1.55, & -1.90 & -2.43 & -2.66 \\
\hline \multirow{3}{*}{ Italy } & ב--- & 2.71 & 1.93 & 1.92 & 1.29 ' & 0.51 ' & -0.15, & -0.65, & -1.02, & -1.31, & -1.65 & -1.78 \\
\hline & 1 & 2.14 & 1.96 & 1.67 & 1.06' & 0.23 & $-0.47^{\prime}$ & $-0.99^{\prime}$ & -1.37 & -1.65 & -1.88 & -2.09 \\
\hline & $(1, t)^{\prime}$ & 2.31 & 1.90 & 1.74 & 1.30' & 0.47 & $-0.34^{\prime}$ & -0.96, & -1.37, & -1.66 & -1.89 & -2.09 \\
\hline \multirow{3}{*}{ Germany } & --- & 1.67 & $1.46^{\prime}$ & 0.87 & 0.18, & -0.39 ' & -0.82, & -1.13, & -1.66 & -1.75 & -1.82 & -1.87 \\
\hline & 1 & 1.97 & 1.22 ' & 0.69 ' & 0.04 & $-0.51^{\prime}$ & -0.92 & -1.23, & $-1.46^{\prime}$ & -1.65 & -1.81 & -1.96 \\
\hline & $(1, t)^{\prime}$ & 2.33 & 1.31 ' & 0.88, & 0.26 , & -0.35, & $-0.84^{\prime}$ & $-1.20^{\prime}$ & -1.65 & -1.95 & -2.01 & -2.06 \\
\hline \multirow{3}{*}{ U. K. } & --- & 0.40 , & 0.14 & -0.28, & -0.69, & -0.99 ' & -1.19 & 1-32, & -1.67 & -1.77 & -1.83 & -2.06 \\
\hline & 1 & 0.18 , & -0.03, & -0.62 & $-1.20^{\prime}$ & $-1.62^{\prime}$ & -1.89 & -2.07 & -2.18 & -2.25 & -2.30 & -2.35 \\
\hline & $(1, t)^{\prime}$ & 0.39' & 0.09 & -0.43, & $-1.00^{\prime}$ & -1.48, & -1.82 & -2.04 & -2.17 & -2.25 & -2.31 & -2.36 \\
\hline
\end{tabular}

' and in bold: Non-rejection values at the $95 \%$ significance level. 


\begin{tabular}{|c|c|c|c|c|c|c|c|}
\hline \multicolumn{8}{|c|}{ TABLE 4} \\
\hline \multicolumn{8}{|c|}{ Selected model for each country according to the lowest statistic across $d_{o}$} \\
\hline Country & $\mathrm{u}_{\mathrm{t}}$ & $\mathrm{z}_{\mathrm{t}}$ & $\mathrm{d}_{\mathrm{o}}$ & $\alpha$ & $\beta$ & $\alpha_{1}$ & $\alpha_{2}$ \\
\hline \multirow{9}{*}{ France } & \multirow{3}{*}{ White noise } & --- & 1.34 & --- & --- & --- & --- \\
\hline & & 1 & 1.37 & 438.58 & --- & --- & --- \\
\hline & & $(1, \mathrm{t})^{\prime}$ & 1.38 & 415.67 & 45.55 & --- & --- \\
\hline & \multirow{3}{*}{$\mathrm{AR}(1)$} & --- & 1.35 & --- & --- & -0.02 & --- \\
\hline & & 1 & 1.30 & 437.87 & --- & 0.11 & --- \\
\hline & & $(1, t)^{\prime}$ & 1.35 & 412.61 & 49.82 & 0.11 & --- \\
\hline & \multirow{3}{*}{$\mathrm{AR}(2)$} & --- & 1.55 & --- & --- & -0.23 & -0.20 \\
\hline & & 1 & 1.42 & 439.04 & --- & -0.003 & -0.14 \\
\hline & & $(1, \mathrm{t})^{\prime}$ & 1.44 & 419.07 & 40.12 & -0.01 & -0.14 \\
\hline \multirow{9}{*}{ Italy } & \multirow{3}{*}{ White noise } & (--- & 1.30 & --- & --- & --- & (--- \\
\hline & & 1 & 1.31 & 52846.45 & --- & --- & --- \\
\hline & & $(1, t)^{\prime}$ & 1.33 & 48156.29 & 9261.37 & --- & --- \\
\hline & \multirow{3}{*}{$\mathrm{AR}(1)$} & --- & 1.33 & --- & --- & -0.05 & --- \\
\hline & & 1 & 1.32 & 52862.38 & --- & -0.02 & --- \\
\hline & & $(1, t)^{\prime}$ & 1.35 & 48361.98 & 8952.81 & -0.04 & --- \\
\hline & \multirow{3}{*}{$\mathrm{AR}(2)$} & --- & 1.47 & --- & --- & -0.21 & -0.20 \\
\hline & & 1 & 1.43 & 52990.76 & --- & -0.14 & -0.17 \\
\hline & & $(1, \mathrm{t})^{\prime}$ & 1.46 & 49581.73 & 6837.85 & -0.16 & -0.17 \\
\hline \multirow{9}{*}{ Germany } & \multirow{3}{*}{ White noise } & --- & 1.32 & --- & --- & --- & --- \\
\hline & & 1 & 1.33 & 89.26 & --- & --- & --- \\
\hline & & $(1, t)^{\prime}$ & 1.34 & 78.74 & 20.77 & --- & --- \\
\hline & \multirow{3}{*}{$\mathrm{AR}(1)$} & --- & 1.16 & --- & --- & 0.28 & --- \\
\hline & & 1 & 1.14 & 88.51 & --- & 0.31 & --- \\
\hline & & $(1, t)^{\prime}$ & 1.16 & 74.63 & 23.93 & 0.30 & --- \\
\hline & \multirow{3}{*}{$\mathrm{AR}(2)$} & --- & 1.33 & --- & --- & 0.15 & -0.25 \\
\hline & & 1 & 1.31 & 89.17 & --- & 0.19 & -0.25 \\
\hline & & $(1, \mathrm{t})^{\prime}$ & 1.34 & 78.74 & 20.77 & 0.17 & -0.25 \\
\hline \multirow{9}{*}{ U. K. } & \multirow{3}{*}{ White noise } & "--- & 1.29 & "--- & --- & --- & --- \\
\hline & & 1 & 1.36 & 51.13 & --- & --- & --- \\
\hline & & $(1, \mathrm{t})^{\prime}$ & 1.38 & 49.08 & 4.03 & --- & --- \\
\hline & \multirow{3}{*}{$\mathrm{AR}(1)$} & --- & 1.12 & --- & --- & 0.28 & --- \\
\hline & & 1 & 1.08 & 51.51 & --- & 0.43 & --- \\
\hline & & $(1, t)^{\prime}$ & 1.11 & 48.39 & 4.66 & 0.40 & --- \\
\hline & \multirow{3}{*}{$\mathrm{AR}(2)$} & --- & 1.14 & --- & --- & 0.26 & -0.02 \\
\hline & & 1 & 1.09 & 51.47 & --- & 0.42 & -0.02 \\
\hline & & $(1, t)^{\prime}$ & 1.12 & 48.44 & 4.66 & 0.40 & -0.02 \\
\hline
\end{tabular}




\section{TABLE 5}

Mean square erros of the selected models for the last 10 out-of-sample observations

\begin{tabular}{|c|c|c|c|c|c|c|c|c|c|c|c|c|}
\hline & & & \multicolumn{10}{|c|}{ Out of sample observations } \\
\hline Country & $\mathrm{u}_{\mathrm{t}}$ & $\mathrm{z}_{\mathrm{t}}$ & 1991 & 1992 & 1993 & 1994 & 1995 & 1996 & 1997 & 1998 & 1999 & 2000 \\
\hline \multirow{9}{*}{ France } & \multirow{3}{*}{$\begin{array}{l}\text { White } \\
\text { noise }\end{array}$} & --- & 0.006 & 0.216 & 0.045 & 0.350 & 0.907 & 1.697 & 2.436 & 2.916 & 3.557 & 4.036 \\
\hline & & 1 & 0.125 & 0.822 & 0.047 & 0.036 & 0.339 & 0.934 & 1.584 & 2.071 & 2.724 & 3.260 \\
\hline & & $(1, t)^{\prime}$ & 36.701 & 30.791 & 39.525 & 45.524 & 51.777 & 58.302 & 63.740 & 67579 & 72.049 & 75.683 \\
\hline & \multirow{3}{*}{$\operatorname{AR}(1)$} & --- & 0.006 & 0.216 & 0.046 & 0.366 & 0.956 & 1.794 & 2.589 & 3.124 & 3.829 & 4.371 \\
\hline & & 1 & 0.260 & 0.006 & 0.293 & 0.924 & 1.622 & 2.482 & 3.188 & 3.557 & 4.077 & 4.403 \\
\hline & & $(1, t)^{\prime}$ & 43.113 & 36.919 & 46.128 & 51.835 & 57.561 & 63.410 & 68.016 & 70.912 & 74.418 & 77.045 \\
\hline & \multirow{3}{*}{$\operatorname{AR}(2)$} & --- & 0.010 & 0.246 & 0.016 & 0.326 & 1.110 & 2.412 & 3.903 & 5.275 & 7.048 & 8.764 \\
\hline & & 1 & 0.268 & 0.012 & 0.416 & 1.175 & 2.310 & 3.809 & 5.258 & 6.371 & 7.761 & 8.949 \\
\hline & & $(1, t)^{\prime}$ & 29.112 & 23.652 & 31.311 & 37.000 & 43.208 & 49.865 & 55.607 & 60.074 & 65.152 & 69.497 \\
\hline \multirow{9}{*}{ Italy } & \multirow{3}{*}{$\begin{array}{l}\text { White } \\
\text { noise }\end{array}$} & --- & 0.075 & 2.265 & 8.772 & 31.243 & 55.171 & 97.258 & 135.63 & 174.52 & 211.84 & 236.52 \\
\hline & & 1 & 3.828 & 0.030 & 22.164 & 55.131 & 87.521 & 141.12 & $189 . .08$ & 237.12 & 283.04 & 314.18 \\
\hline & & $(1, t)^{\prime}$ & 1409.1 & 1299.5 & 1670.8 & 1925.9 & 2126.0 & 2393.7 & 2610.7 & 2812.2 & 2997.4 & 3129.6 \\
\hline & \multirow{3}{*}{$\operatorname{AR}(1)$} & --- & 0.094 & 2.205 & 10.045 & 36.680 & 66.668 & 118.07 & 166.65 & 216.78 & 265.99 & 301.56 \\
\hline & & 1 & 3.872 & 0.032 & 22.820 & 57.446 & 92.180 & 149.19 & 200.84 & 252.91 & 303.06 & 338.09 \\
\hline & & $(1, t)^{\prime}$ & 1324.7 & 1216.4 & 1593.4 & $1870-2$ & 2098.4 & 2397.6 & 2648.0 & 2885.9 & 3108.9 & 3276.0 \\
\hline & \multirow{3}{*}{$\operatorname{AR}(2)$} & --- & 0.179 & 2.083 & 12.653 & 52.499 & 106.61 & 197.73 & 294.55 & 401.55 & 514.38 & 614.07 \\
\hline & & 1 & 4.234 & 0.045 & 27.089 & 76.368 & 135.53 & 222.55 & 321.99 & 421.04 & 532.34 & 610.02 \\
\hline & & $(1, t)^{\prime}$ & 804.24 & 713.45 & 1019.6 & 1281.4 & 1524.3 & 1844.5 & 2134.5 & 2422.9 & 2704.5 & 2944.2 \\
\hline \multirow{9}{*}{ Germany } & \multirow{3}{*}{$\begin{array}{l}\text { White } \\
\text { noise }\end{array}$} & --- & 0.064 & 0.144 & 0.009 & 0.002 & 0.046 & 0.125 & 0.198 & 0.257 & 0.347 & 0.407 \\
\hline & & 1 & 0.116 & 0.217 & 0.031 & 0.005 & 0.120 & 0.182 & 0.147 & 0.203 & 0.289 & 0.349 \\
\hline & & $(1, t)^{\prime}$ & 5.580 & 5.097 & 6.608 & 7.571 & 8.667 & 9.699 & 10.485 & 11.094 & 11.850 & 12.407 \\
\hline & \multirow{3}{*}{$\operatorname{AR}(1)$} & --- & 0.063 & 0.140 & 0.033 & 0.017 & 0.044 & 0.133 & 0.209 & 0.206 & 0.303 & 0.401 \\
\hline & & 1 & 6.668 & 0.092 & 0.011 & 0.005 & 0.004 & 0.003 & 0.002 & 0.009 & 0.001 & 0.001 \\
\hline & & $(1, t)^{\prime}$ & 30.142 & 7.001 & 8.206 & 8.635 & 9.167 & 9.616 & 9.820 & 9.865 & 10.068 & 10.084 \\
\hline & \multirow{3}{*}{$\operatorname{AR}(2)$} & --- & 0.061 & 0.154 & 0.013 & 0.001 & 0.042 & 0.120 & 0.105 & 0.157 & 0.251 & 0.315 \\
\hline & & 1 & 0.025 & 0.091 & 0.001 & 0.012 & 0.071 & 0.156 & & 0.287 & 0.374 & 0.428 \\
\hline & & $(1, t)^{\prime}$ & 5.604 & 5.040 & 6.492 & 7.441 & 8.525 & 9.535 & 10.300 & 10.892 & 11.640 & 12.176 \\
\hline \multirow{9}{*}{ U. K. } & \multirow{3}{*}{$\begin{array}{l}\text { White } \\
\text { noise }\end{array}$} & --- & 0.310 & 1,613 & 0.140 & 0.005 & 0.389 & 1.360 & 1.845 & 2.834 & 4.716 & 5.607 \\
\hline & & 1 & 1.100 & 8.830 & 4.117 & 2.020 & 0.507 & 0.001 & 0.149 & 0.794 & 2.422 & 3.706 \\
\hline & & $(1, t)^{\prime}$ & 312.14 & 251.93 & 287.03 & 311.86 & 342.75 & 375.01 & 394.71 & 420.25 & 453.37 & 474.75 \\
\hline & \multirow{3}{*}{$\operatorname{AR}(1)$} & --- & 0.297 & 1.466 & 0.726 & 1.056 & 1.139 & 1.159 & 1.950 & 2.401 & 2.278 & 3.011 \\
\hline & & 1 & 4.176 & 0.176 & 0.325 & 0.044 & 0.023 & 0.015 & 0.316 & 0.673 & 0.767 & 1.413 \\
\hline & & $(1, t)^{\prime}$ & 397.45 & 339.64 & 356.53 & 353.68 & 356.22 & 360.14 & 352.47 & 351.23 & 357.23 & 353.54 \\
\hline & \multirow{3}{*}{$\operatorname{AR}(2)$} & --- & 0.205 & 1.487 & 0.590 & 0.733 & 0.672 & 0.580 & 1.044 & 1.255 & 1.062 & 1.465 \\
\hline & & 1 & 4.173 & 0.197 & 0.375 & 0.090 & 0.020 & 0.001 & 0.140 & 0.368 & 0.407 & 0.866 \\
\hline & & $(1, t)^{\prime}$ & 397.53 & 333.91 & 346.96 & 340.34 & 338.81 & 338.43 & 326.72 & 321.19 & 322.61 & 314.51 \\
\hline
\end{tabular}

In bold, the lowest mean square error across the different models for each period. 
